\title{
Recent Biomimetic and Organocatalytic Syntheses of $\alpha$-Tocopherol
}

\author{
Antoinette Chougnet, Kegang Liu, and Wolf-D. Woggon*
}

\begin{abstract}
We report here on our efforts to develop new strategies for the synthesis of $\alpha$-tocopherol, the biologically most significant member of the vitamin $\mathrm{E}$ family. This review comprises five new methods to generate the chiral chromane of $\alpha$-tocopherol with overall up to $29 \%$ yield from commercially available material and up to $94 \% d e$.
\end{abstract}

Keywords: Chromane $\cdot$ Enantioselectivity $\cdot \alpha$-Tocopherol $\cdot$ Tocopherol cyclase $\cdot$ Vitamin E

\section{Introduction}

Vitamin E comprises tocopherols 1-4 and tocotrienols 5-8 which can be isolated from all photosynthetic organisms (Fig. 1). These compounds exhibit various physiologically significant properties such as the modulation of signal transduction, ${ }^{[1]}$ antiinflammatory action ${ }^{[2]}$ and antioxidant reactivity. ${ }^{[3]}$

$\alpha$-Tocopherol (1) is the biologically most important member of the vitamin $\mathrm{E}$ family as it acts as the best radical chainbreaking antioxidant in tissues ${ }^{[4]}$ and binds selectively to a transport protein ${ }^{[5]}$ providing efficient bioavailability. The antioxidant reactivity of the chromanol system has been investigated in detail ${ }^{[3]}$ and is attributed to stereoelectronic factors, i.e. the lone pair of $\mathrm{O}(1)$ is favorably oriented to stabilize the tocopheryl radical 9 produced by homolysis of the phenolic $\mathrm{OH}$ group (Scheme 1).

The isolation of pure $\mathbf{1}$ from natural sources is quite difficult because the compound appears in various amounts along with other vitamin E chromanols.
${ }^{\star}$ Correspondence: Prof. Dr. W.-D. Woggen Department of Chemistry

University of Basel

St. Johanns-Ring 19

$\mathrm{CH}-4056$ Basel

Tel.: +41612671104

Fax: +41612671103

E-mail: wolf-d.woggon@unibas.ch

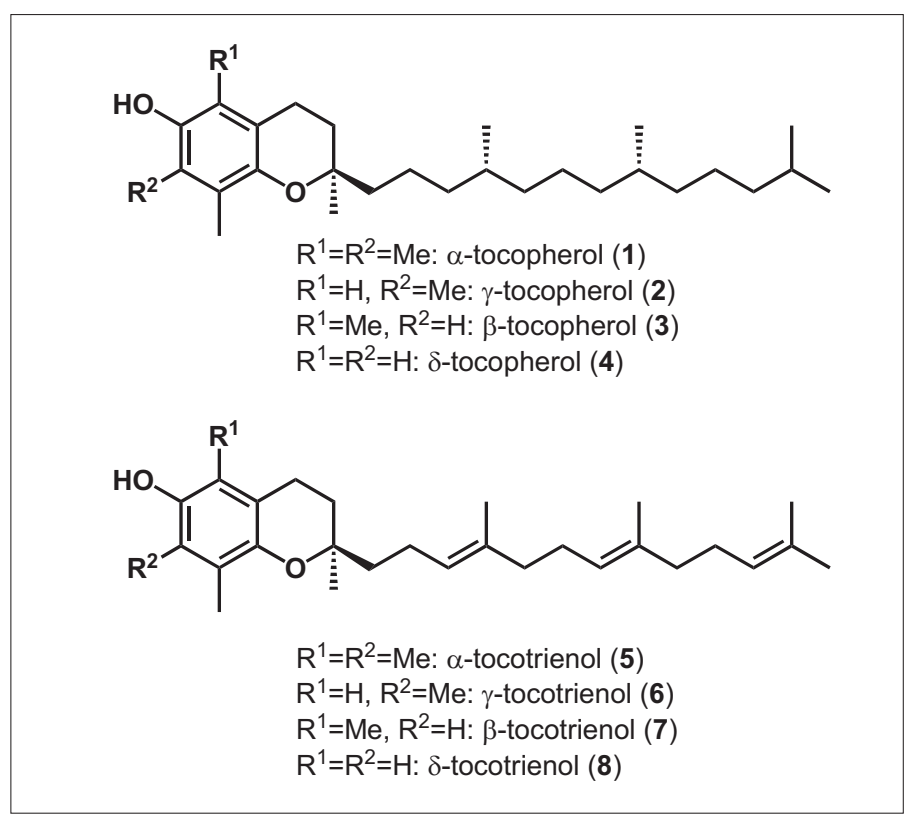

Fig. 1. Structures of vitamin E compounds.

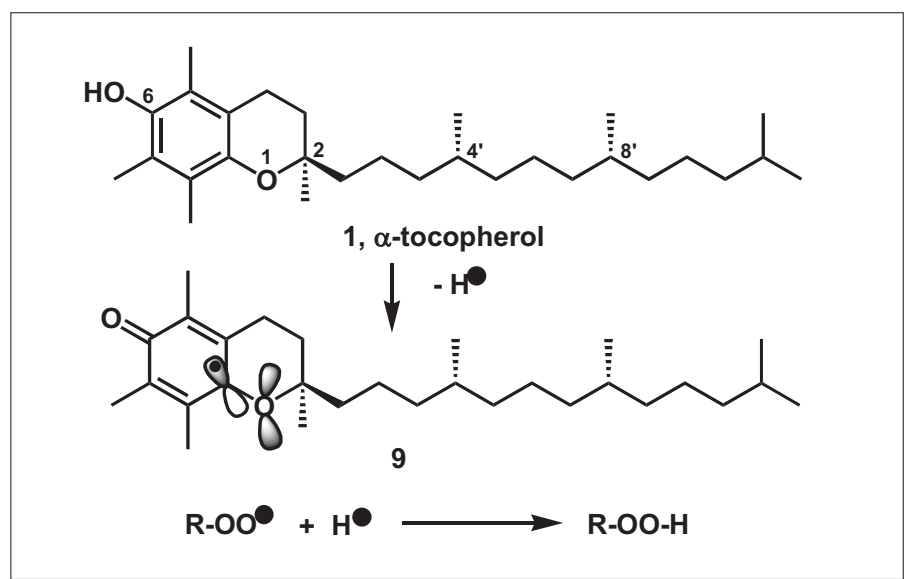

Scheme 1.

Antioxidant reactivity of 1: Formation of tocopheryl radicals such as $\mathbf{9}$ and trapping of peroxy radicals $\mathrm{ROO}$ that are produced under oxidative stress in membranes for example.

The challenge to prepare chiral 1 results from the presence of stereogenic centers at $\mathrm{C}(2), \mathrm{C}\left(4^{\prime}\right)$, and $\mathrm{C}\left(8^{\prime}\right)$. A comprehensive review by Netscher describes the syntheses of racemic and enantiomerically enriched tocopherols up to 2006. [6] Since then we have developed several new approaches to chiral chromanols that are reviewed here.

\section{Results and Discussion}

\subsection{Biomimetic Synthesis of $\alpha$ - Tocopherol and $\alpha$-Tocotrienol}

The discovery of the enzyme tocopherol cyclase from Cyanobacteria ${ }^{[7]}$ and investigations of the substrate specificity $^{[8]}$ and reaction mechanism ${ }^{[9]}$ revealed that i) the enzyme cyclizes hydroquinone 
precursors with chiral and unsaturated side chains leading to $\mathbf{2}$ and $\mathbf{6}$, respectively, with the comparable efficiency; and ii) the very hydrophobic $42 \mathrm{kD}$ protein operates by $s i$ protonation of the double bond and concomitant re attack of the phenol (Scheme 2).

In view of the weak acidity of amino acids available in the active site of the protein it was suggested ${ }^{[10]}$ that substrates such as $\mathbf{1 0}$ bind to the enzyme in a high energy conformation (Scheme 2) in which both phenol and proton source are in binding distance of the double bond. This insight led to a biomimetic synthesis of $\alpha$-tocopherol (1) using a large protecting group $R$ and a dipeptide as steric constraints to generate a suitable conformation of the hydroquinone and providing a proton source, ${ }^{[11]}$ see 11 (Scheme 3).

The general strategy to obtain a suitable precursor for cyclization to the chromanol system of vitamin $\mathrm{E}$ is outlined in Fig. 2. It was anticipated that cyclization would proceed with the chiral side chain leading directly to $\mathbf{1}$ as well as with the unsaturated side chain yielding $\alpha$-tocotrienol (5) that could be enantioselectively hydrogenated to 1 using established methods. ${ }^{[11]}$

Accordingly, the synthesis of $\mathbf{1}$ started with the monoprotected hydroquionone $\mathbf{1 3}$ which underwent a Mannich reaction with the proline derivative 14 (Scheme 4). ${ }^{[12]}$ Subsequent esterification with camphanoyl chloride and deprotection gave $\mathbf{1 5}$ to which the protected aspartate $\mathbf{1 6}$ was added. The resulting phytyl phenol $\mathbf{1 7}$ was cyclized in the presence of pTsOH and furnished the protected chromanol dipeptide $\mathbf{1 8}$ in excellent yield. The benzylic amine of $\mathbf{1 8}$ was removed by hydrogenation and the $\left(2 R, 4^{\prime} R, 8^{\prime} R\right)$-tocopherylester 19a obtained displaying $70 \%$ de (diasteromeric excess). Systematic investigation of the cyclization reaction revealed that i) the $d e$ is independent of the camphanoyl unit (useful for de determination of the final product), ii) the de depends on the chirality of the dipeptide. For example if $(S)$-proline/ $(S)$-aspartate were employed the $\left(2 S, 4^{\prime} R, 8^{\prime} R\right)$-tocopheryl camphanate was obtained displaying $80 \%$ de. A similar reaction sequence was used to yield $\alpha$-tocotrienyl acetatel $(\mathbf{2 0}, 65 \%$ de) which was subsequently hydrogenated to $\mathbf{1 9 b}$ in the presence of the catalyst 21. .11] $^{\text {. }}$

The conversion of hydroquinone precursors such as $\mathbf{1 7}$ to chromanols gave surprisingly high de values given the fact that the flexibly attached dipeptide is the only chirality inducing unit. To a certain extent this result validates the proposal that in the active site of tocopherol cyclase a high energy conformer of the phytylhydroquinone can cyclize even in the presence of weak acids.

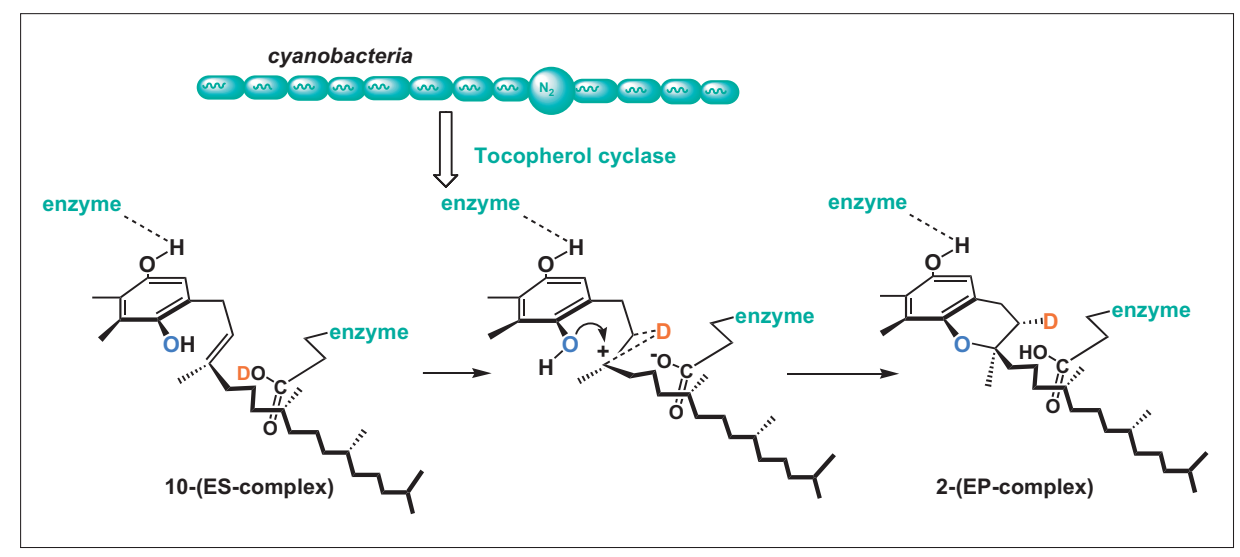

Scheme 2. Reaction mechanism of tocopherol cyclase.

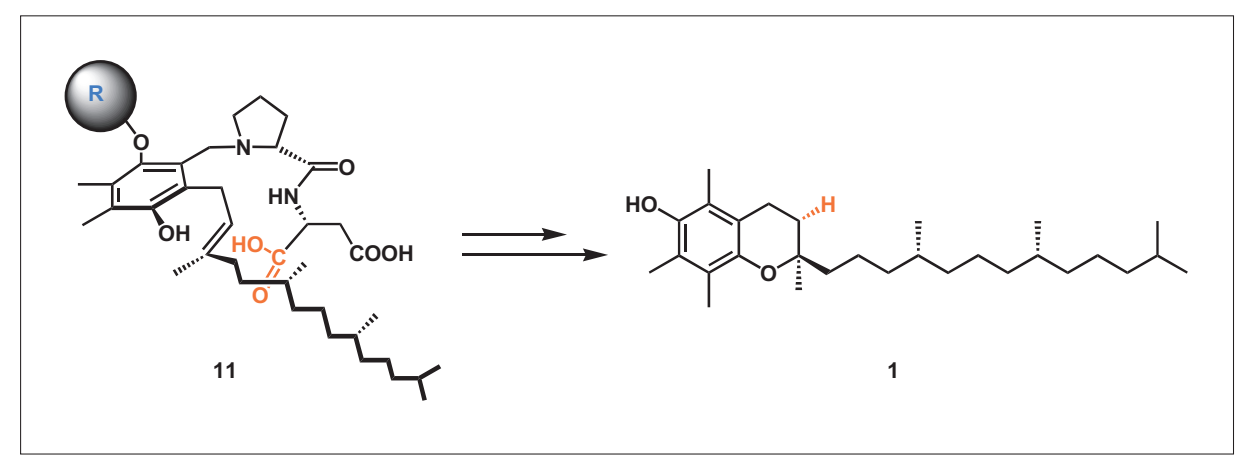

Scheme 3. Biomimetic approach to $\alpha$-tocopherol (1).

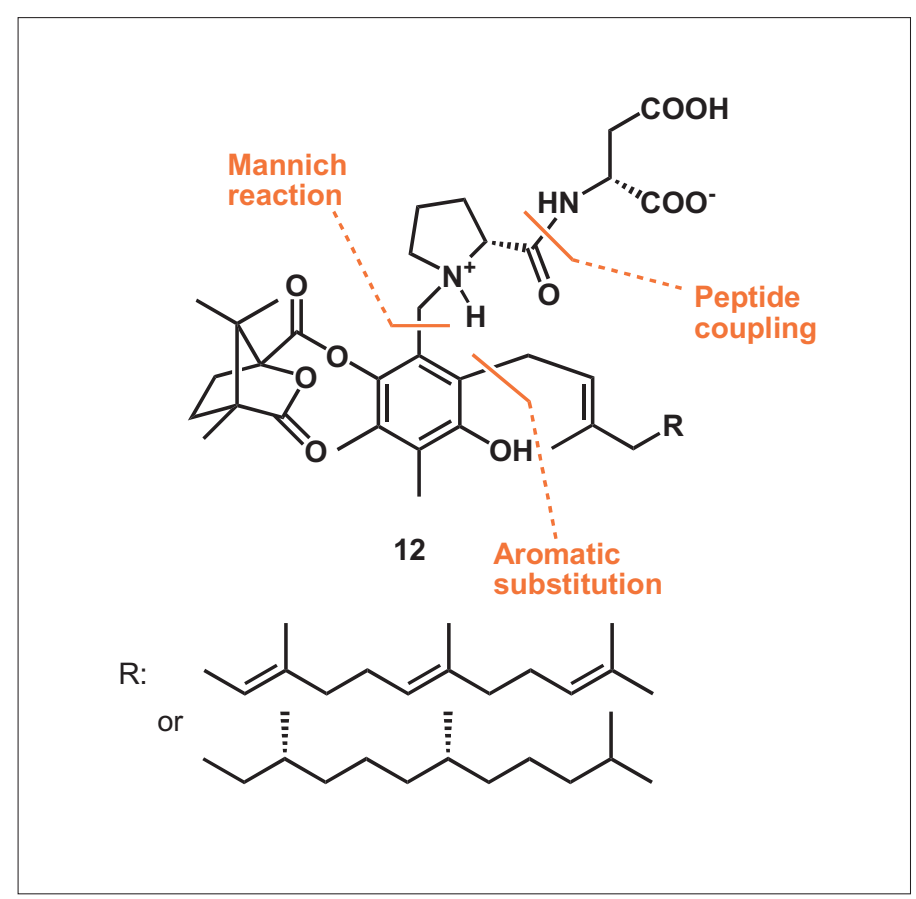

Fig. 2. Retrosynthetic analysis to generate the allylic phenol 12 for cyclization.

\subsection{Organocatalytic Keysteps for the Synthesis of Chromanols 2.2.1 Organocatalysis Using Chiral Dioxetans}

The retrosynthetic plan of this approach to $\alpha$-tocopherol (1) is depicted in Scheme 5. The sequence poses two problems: i) enantioselective epoxidation of a triply substituted double bond lacking ad- jacent functionalization, see 22, and ii) regioselective, 'anti-Baldwin' ring opening of the epoxide $\mathbf{2 3}$ to form the 6-membered chromane system $\mathbf{2 4}$ without racemization.

Regarding enantioselective epoxidation we considered the application of organocatalysts developed by Zhao and Shi.[13] This group has reported that fructose-derived compounds such as $\mathbf{2 5}\left(+\mathrm{H}_{2} \mathrm{O}_{2}\right)$ cata- 
<smiles>[R]C/C(C)=C/Cc1cc(O)c(C)c(C)c1OC1CCCCO1</smiles><smiles>C=[N+]1CCCC1C(=O)OC</smiles>

2

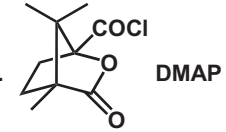<smiles>[R]CC(C)=CCc1c(O)c(C)c(C)c(O[R])c1CN1CCC[C@H]1C(=O)O</smiles><smiles>[R]Oc1c(C)c(C)c2c(c1C[N+]13CCC[NH+]1CC3C(=O)N[C@H](CC(=O)O)C(=O)O)CC[C@@H](C)O2</smiles><smiles>[R]Oc1c(C)c(C)c2c(c1C)CC[C@H](CCCC[C@H](C)CCC[C@H](C)CCCC(C)C)O2</smiles><smiles>CC1(C)C2CCC(C(=O)O2)C1(C)C</smiles>
$\mathrm{H}_{2}, 50 \mathrm{bar}, 95 \%$<smiles>CC(=O)Oc1c(C)c(C)c2c(c1C)CC[C@@](C)(CCC=C(C)CCC=C(C)CCC=C(C)C)O2</smiles>

Scheme 4. Biomimetic synthesis of $\alpha$-tocopheryl- and $\alpha$-tocotrinenyl esters.<smiles>[R]Oc1c(C)c2c(c(C)c1C=C)O[C@]([R])(C)[C@@H](O)C2</smiles><smiles>[R7]Oc1c(C)c(C)c(OCC)c(CC2OC2([R2])C)c1C</smiles>
23

$\mathbf{R}$<smiles>CCC[C@H](C)CCC[C@H](C)CCCC(C)C</smiles>

enantioselective epoxidation<smiles>[R]Oc1c(C)c(C)c(O[R])c(CC=C([R])C)c1C</smiles>

22

Scheme 5. Retrosynthesis in order to obtain chiral chromanols via regioselective epoxide ring opening.

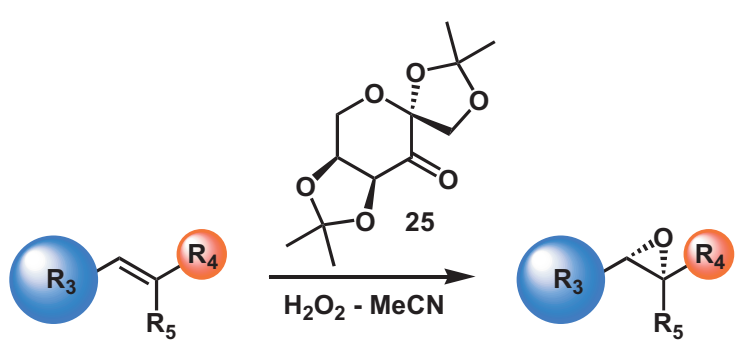

Scheme 6. Chiral dioxetanes generated from ketones such as $\mathbf{2 5}$ epoxidizing non-functionalized olefins.

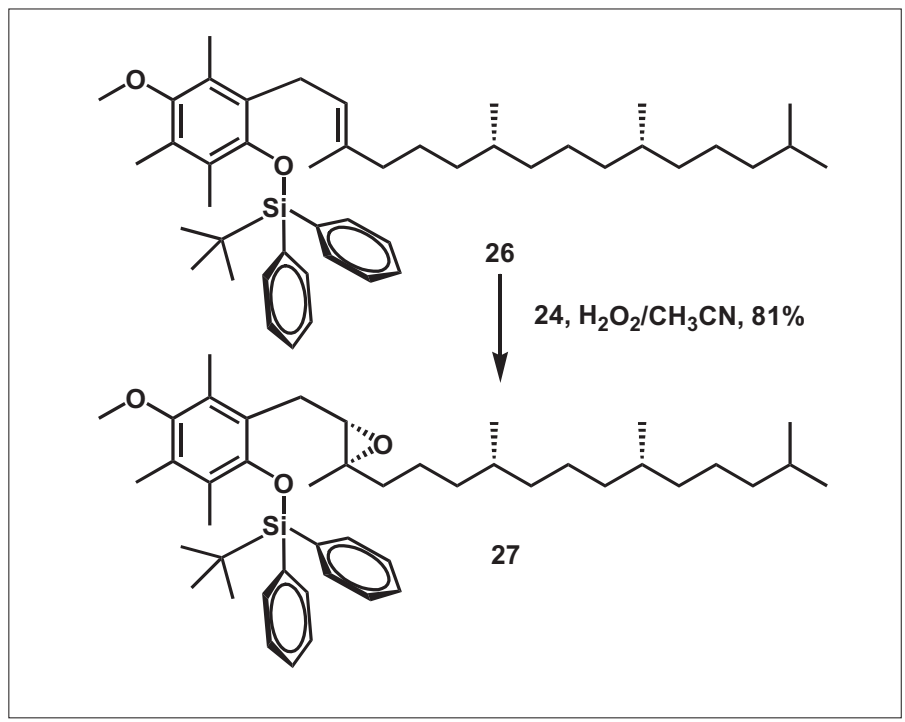

Scheme 7. Diastereoselective 'Shi-epoxidation'.

lyze the formation of chiral epoxides provided the olefin contains groups $\mathrm{R}_{3}$ and $\mathrm{R}_{4}$ that are very different in size (Scheme 6).

In principle this is not the case for olefin 22 as both groups adjacent to the double are $\mathrm{CH}_{2}$. Nevertheless, we believed we could optimize the substrate through the substituents at the hydroquinone. Screening substrates with nine variations for $\mathrm{R}_{1} /$ $\mathrm{R}_{2}$ we found one outstanding result for $\mathbf{2 6}$ which gave epoxide 27 in $81 \%$ yield and 97\% de (Scheme 7).

In order to accomplish the formation of the chromane system under inversion of configuration we first used conditions reported by Vilotijevic and Jamison ${ }^{[14]}$ which favored pyran products in $\mathrm{MeOH}$. However, a mono-protected epoxyphytyl hydroquinone gave exclusively the furan product following Baldwin's rule. ${ }^{[15]}$ A systematic investigation (21 experiments) of the epoxide ring opening finally revealed that the epoxide $\mathbf{2 8}$ could be cyclized in acetonitrile/2M HCl-ether to the 3-hydroxy chromane 29 in $79 \%$ yield (Scheme 8). Removal of the hydroxyl group went smoothly through the corresponding tosylate, easily eliminated 
<smiles>COc1c(C)c(C)c2c(c1C)C[C@H]1O[C@]1(CCC[C@H](C)CCC[C@H](C)CCCC(C)C)O2</smiles><smiles>COc1c(C)c(C)c2c(c1C)C[C@H](O)[C@H](CCC[C@H](C)CCCC[C@H](C)CCCC(C)C)O2</smiles>

29

1. $\mathrm{TsCl}, \mathrm{py}, 94 \%$

2. KOtBu, THF, $0^{\circ} \mathrm{C}$;

$\mathrm{Pd} / \mathrm{C}, \mathrm{H}_{2}, 96 \%$

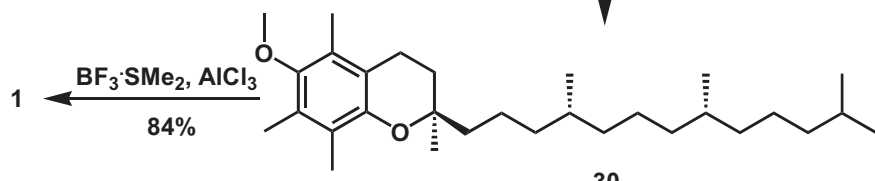

Scheme 8. Chromanol formation through 'anti-Baldwin' ring opening of epoxide 28.

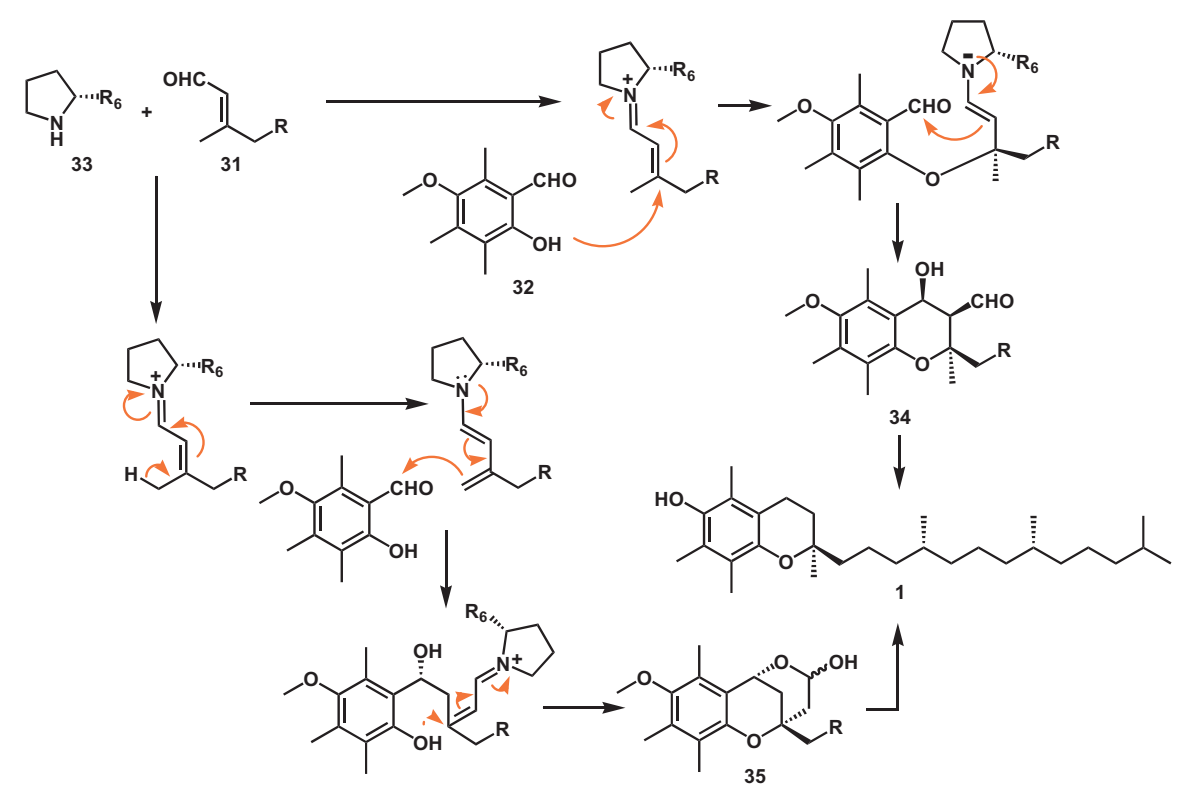

Scheme 9. Proline-catalyzed domino-aldol-oxa-Michael reaction of phytal (31) and salicylaldehyde 32.

and directly hydrogenated to afford $\mathbf{3 0}$ in almost quantitative yield and $93 \%$ de Note that the small decrease of $d e$ from $\mathbf{2 7}$ to $\mathbf{3 0}$ is due to the extent of carbenium ion formation during the conversion of $\mathbf{2 8}$ to 29. Deprotection of $\mathbf{3 0}$ to $\mathbf{1}$ was accomplished by means of $\mathrm{BF} \cdot \mathrm{SMe}_{2} / \mathrm{AlCl}_{3}$ without epimerization at $\mathrm{C}(2)$.

\subsubsection{Organocatalysis Using Proline Derivatives}

In recent years organocatalysts derived from proline have been successfully applied for aldol and Mannich reactions. ${ }^{[16]}$ We considered that a domino-aldol-oxaMichael reaction between phytal $\mathbf{3 1}$ and salicylaldehyde $\mathbf{3 2}$ catalyzed by $\mathbf{3 3}$ for example would either give aldehyde 34 or lactol 35 or a mixture of both (Scheme 9). From both intermediates one could envisage preparing $\alpha$-tocopherol (1) by removal of the $\mathrm{OH}$ and $\mathrm{CHO}$ substituents at the heterocycle. Screening of ten different proline organocatalysts for the reaction between $\mathbf{3 1}$ and $\mathbf{3 2}$ revealed that $\mathbf{3 6}$ (Scheme 10) was the best choice to obtain lactol 35 in $60 \%$ yield and $97 \%$ de; the enantiomer of 36 gave the diasteromeric lactol. ${ }^{[17]}$

The lactol 35 was oxidized to the benzylic lactone 37 which was readily hydrogenated to afford the acid $\mathbf{3 8}$. Only two further steps, i.e. removal of one carbon and de- methylation, are required to convert the key intermediate 38 into $\alpha$-tocopherol (Scheme 10). However conditions had to be carefully tuned to prevent racemization at $\mathrm{C}(2)$ due to thermal or acid-catalyzed ring opening/ring closure of the chromane system. Finally two procedures were found for the chain cleavage at $\mathrm{C}(2)$. Reduction of the acid $\mathbf{3 8}$ followed by oxidation gave the aldehyde 39 in $\mathbf{7 5 \%}$ yield. Subsequent Rh-catalyzed decarbonylation $^{[18]}$ furnished the tocopherol ether $\mathbf{3 0}$ in $80 \%$ yield, $93 \%$ de. The same compound was obtained from 38 in $72 \%$ yield, $94 \%$ de using a Barton decarboxylation procedure. [19] Ether cleavage was accomplished by treating 30 with $\mathrm{BF}_{3} \cdot \mathrm{Me}_{2} \mathrm{~S} / \mathrm{AlCl}_{3}$; $\alpha$-tocopherol (1) was obtained in $84 \%$ yield under retention of configuration at $\mathrm{C}(2)$.

In summary, although the domino reaction requires rather high concentrations $(30 \mathrm{ml} \%)$ of the proline derivative 36 the stereoselectivity and diastereoselectivity of this step are excellent providing one of the shortest procedures to obtain natural $\alpha$-tocopherol (1). This strategy provides a general access to other members of the vitamin E family and further to various natural products containing highly substituted, chiral chromanols ${ }^{[20]}$ or xanthones. ${ }^{[21]}$

\subsection{Coupling of Phenols with the Side Chain Containing the Re- quired Three Chiral Centers}

Several earlier syntheses of vitamin E compounds reported the preparation of the chiral chromanol using side chains that contain already all chiral centers. ${ }^{[6]}$ Our unprecedented approach ${ }^{[22]}$ employed the chiral key intermediate $\mathbf{4 0}$ which was planned to react under Mitsunobu conditions with phenols $\mathbf{4 1}$ and $\mathbf{4 2}$ generating chiral phenolethers 43 and $\mathbf{4 4}$ that could be further elaborated for the preparation of 1 (Scheme 11). The $\alpha$-hydroxyester 40 was chosen because model reactions revealed that replacement of the ester by $\mathrm{CN}$, $\mathrm{CH}=\mathrm{CH}_{2}, \mathrm{CHO}$ and propargyl substituents was unsatisfactory and gave $<20 \%$ yield of phenol ethers.

Mitsunobu reaction of $\mathbf{4 0}$ with $\mathbf{4 1}$ or $\mathbf{4 2}$ gave phenol ethers 43 and 44 with complete inversion of configuration and $64 \%$ and $68 \%$ yield, respectively. As the thioketal $\mathbf{4 5}$ derived from $\mathbf{4 4}$ did not cyclize in the presence of $\mathrm{nBuLi}^{[23]}$ the corresponding bis-sulfone 46 was prepared ${ }^{[24]}$ that gave the chromane $\mathbf{4 7}$ in $98 \%$ yield on treatment with $\mathrm{NaOMe}$. Reductive removal of the dithiane tetroxide moiety was achieved with excess lithium naphthalenide yielding tocopheryl methylether $\mathbf{3 0}$ in $86 \%$ yield and 94\% de (Scheme 12).

Alternatively $\mathbf{4 3}$ was reduced to aldehyde 48 and subsequent Wittig reaction, hydroboration and oxidation gave aldehyde 49 that cyclized in the presence of TFA to furnish the chromene $\mathbf{5 0}$ in excellent yield 


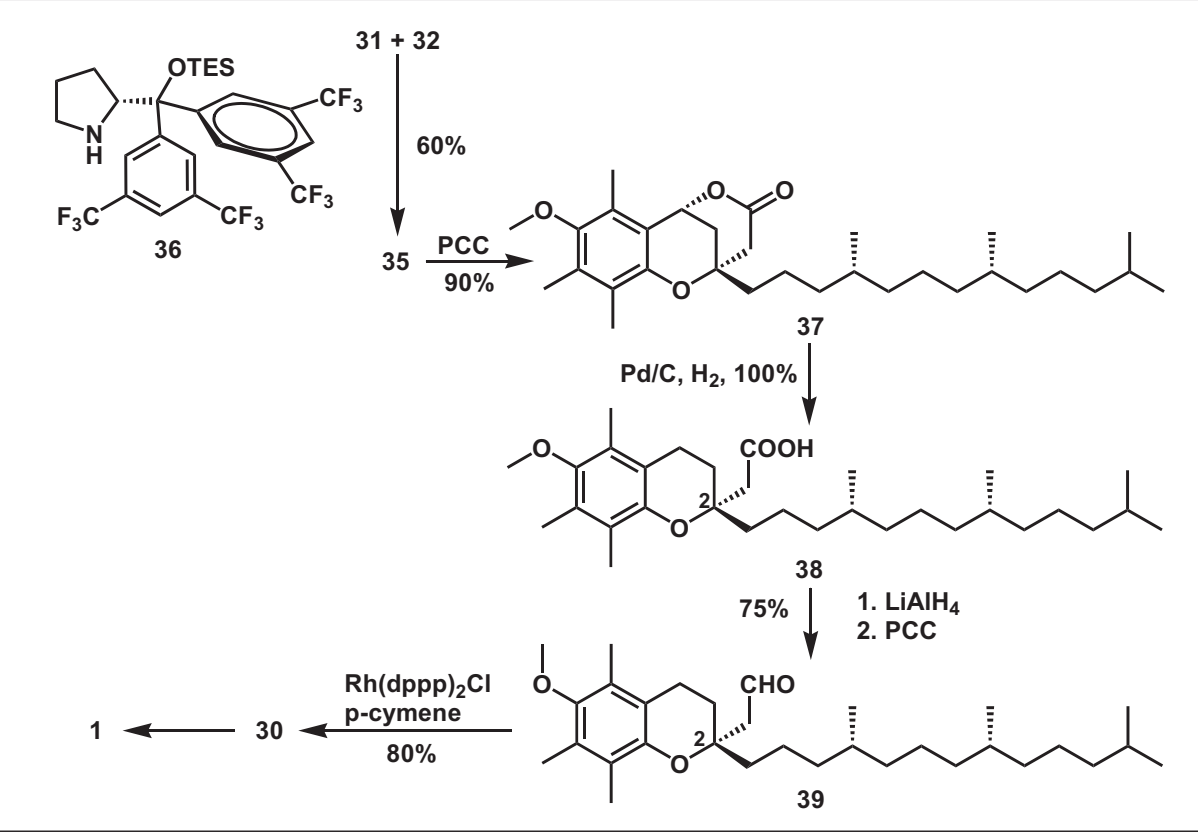

Scheme 10. Organocatalytic synthesis of $\alpha$-tocopherol (1)
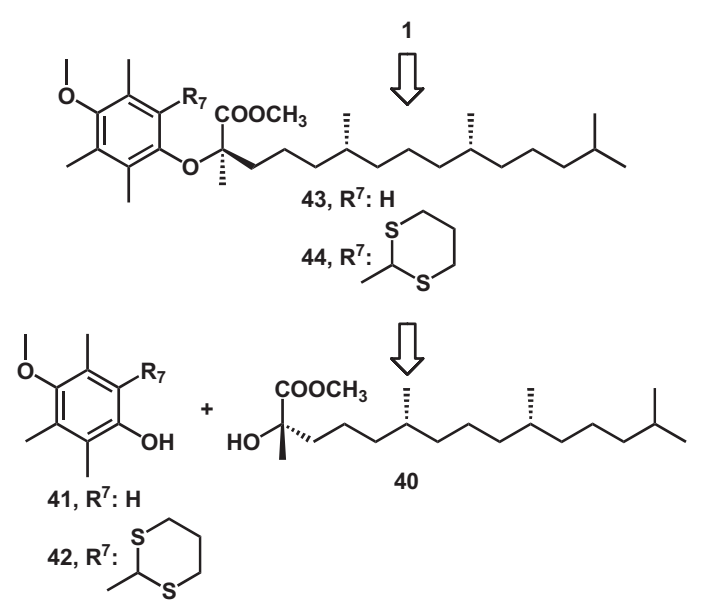

Scheme 11. Retrosynthesis of 1 using the Mitsunobu reaction between phenols and $\alpha$-hydroxyester $\mathbf{4 0}$.
(Scheme 13). Hydrogenation of $\mathbf{5 0}$ followed by deprotection gave $\alpha$-tocopherol (1) displaying 94\% de.

The key step of both pathways to $\alpha$-tocopherol (1) is a carefully controlled Mitsunobu reaction that generates the required phenolether with high $d e$. Consecutive ring closure to the chromane/chromene was accomplished by two different procedures without epimerization.

\section{Conclusion}

Using a phytylhydroquinone derivative that allows for diastereoselective aciddriven double bond activation we developed an enzyme-like formation of the chromanol unit of $\alpha$-tocopherol. Subsequently we employed two organocatalytic reactions as key steps towards diastereoisomerically enriched 1, and further a Mitsunobu reaction was used coupling a suitable phenol with a chiral $\alpha$-hydroxyester under complete inversion of configuration. Except for the biomimetic cyclization all other approaches gave $\mathbf{1}$ displaying de well above $90 \%$.

\section{Acknowledgements}

The research reviewed here includes work of other very talented group members, namely E. Alonso, A. Buss, J. Chapelat, C. Grütter and U. Hengartner. We gratefully acknowledge their contributions and the financial support by the Swiss National Science Foundation, F. Hoffmann-La Roche AG and DSM.

Received: April 6, 2010

[1] J.-M. Zingg, Mol. Asp. Med. 2007, 28, 481.

[2] E. Reiter, Q. Jang, S. Christen, Mol. Asp. Med. 2007, 28, 668 .

[3] G. W. Burton, K. U. Ingold, Acc. Chem. Res. 1986, 19, 194.

[4] G.W. Burton, T. Doba, E. J. Gabe, L. Hughes, F. L. Lee, L. Prasad, K. U. Ingold, J. Am. Chem. Soc. 1985, 107, 7053 .

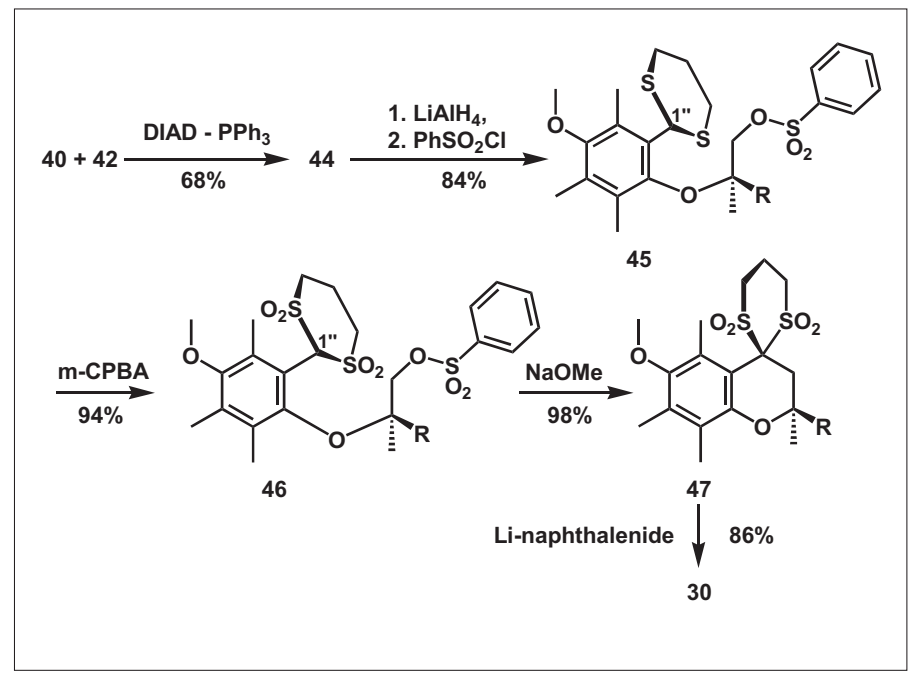

Scheme 12. Chromanol ring closure using the tetraoxido 1,3 dithiane 46.

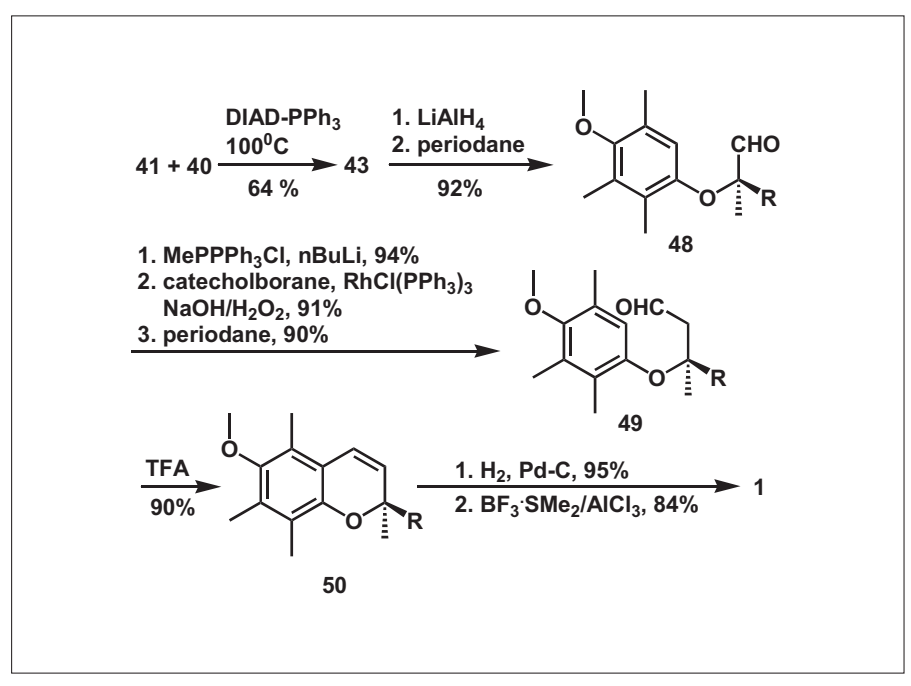

Scheme 13. Chromanol ring closure via electrophilic aromatic substitution. 
[5] R. Meier, T. Tomizaki, C. Schulze-Briese, U. Baumann, A. Stocker, J. Mol. Biology 2003, 331,725 .

[6] T. Netscher in 'Vitamins and Hormones', Vol. 76, Ed. G. Litwack, Elsevier, San Diego, 2007, pp. 155-202.

[7] A. Stocker, A. Rüttimann, W.-D. Woggon, Helv. Chim. Acta 1993, 76, 1729.

[8] A. Stocker, H. Freitz, H. Frick, A. Rüttimann, W.-D. Woggon, Biorg. Med. Chem. 1996, 4, 1129.

[9] A. Stocker, T. Netscher, A. Rüttimann, R. K. Müller, H. Schneider, L. J. Todaro, G. Derungs, W.-D. Woggon, Helv. Chim. Acta 1994, 77, 1721.

[10] C. Grütter, E. Alonso, A. Chougnet, W.-D. Woggon, Angew. Chem., Int. Ed. 2006, 45, 1126.

[11] S. Bell, B. Wüstenberg, S. Kaiser, F. Menges, T. Netscher, A. Pfaltz, Science 2006, 311, 642.

[12] J. Chapelat, A. Chougnet, W.-D. Woggon, Eur. J. Org. Chem. 2009, 2069.

[13] M.-X. Zhao, Y. Shi, J. Org. Chem. 2006, 71, 5377.
[14] I. Vilotijevic, T. F. Jamison, Science 2007, 317, 1189.

[15] J. Baldwin, J. Chem. Soc. Chem. Commun. 1976, 18,734

[16] S. V. Ley, Asymmetric Synthesis 2007, 201.

[17] K. Liu, A. Chougnet, W.-D. Woggon, Angew. Chem., Int. Ed. 2008, 47, 5827.

[18] M. Kreis, A. Palmelund, L. Bunch, R. Madsen, Adv. Synth. Catal. 2006, 348, 2148.

[19] D. H. R. Barton, D. Crich, W. B. Motherwell, Tetrahedron 1985, 41, 3901.

[20] K. Liu, W.-D. Woggon, Eur. J. Org. Chem. 2010, 6, 1033.

[21] N. Volz, M. C. Bröhmer, M. Nieger, S. Bräse, Synlett 2009, 4, 550 .

[22] U. Hengartner, A. Chougnet, K. Liu, W.-D. Woggon, Chem. Eur. J. 2010, 16, 1306.

[23] D. Seebach, E.-M. Wilka, Synthesis 1976, 476

[24] H. Ramuz, Cardiology 1982, 69, 26. 